\title{
Электронейромиографические корреляты синдрома мышечной блокады межпозвонковых дисков у квалифицированных спортсменов
}

\author{
УдК 612.741.16+612.816.3 \\ Е. В. Колосова, Т. А. Халявка, Е. Н. Лысенко
}

Научно-исследовательский институт Национального университета физического воспитания и спорта Украины, Киев, Украина

\begin{abstract}
Резюме. Мета. Дослідити функціональний стан сегментарного апарату поперекового відділу спинного мозку спортсменів, які спеціалізуються у стрибках у воду і біатлоні, і виявити його можливі функціональні і структурні порушення за допомогою методів електронейроміографії. Методи. Визначення швидкості проведення нервового імпульсу по моторних волокнах великогомілкових нервів нижніх кінцівок (n.tibialis), а також методику H-рефлексометрії («Nicolet Viking Select», США-Німеччина).

Результати. В першій групі ЕНМГ-параметри знаходилися в межах норми, в той час як у другій групі спостерігалися значні відхилення показників від нормальних значень: збільшення співвідношення порогів Н- і М-відповідей, зниження амплітуд Н-відповідей і співвідношень амплітуд Н- і М-відповідей. Однак параметри М-відповідей, а також значення швидкостей проведення імпульсу по моторних волокнах n.tibialis не мали достовірних відмінностей в двох групах. Подібні відхилення ЕНМГ-параметрів від норми виникали внаслідок впливу на спинномозкові нерви сегментів $\mathrm{L}_{4}-\mathrm{S}_{3}$ комплексу чинників - компресії, ішемії і гіпоксії, які мають місце при синдромі м'язової блокади міжхребцевих дисків. Ймовірно, патологічні зміни стосувалися в основному структур аферентної частини дуги моносинаптичного рефлексу, що є більш сприйнятливою до компресії. Причиною виникнення синдрому м'язової блокади міжхребцевих дисків могло бути неадекватне навантаження на попереково-крижовий відділ хребта.

Висновки. У 17-28 \% досліджуваних спортсменів спостерігаються відхилення ЕНМГ-параметрів від норми, що може служити діагностичною ознакою синдрому м'язової блокади міжхребцевих дисків на рівні сегментів $L_{4}-S_{3}$ спинного мозку, викликаного впливом неадекватного навантаження на поперековий відділ хребта.
\end{abstract}

Ключові слова: електронейроміографія, нервово-м'язовий апарат, Н-рефлекс, спортсмени, синдром м'язової блокади міжхребцевих дисків.

Abstract. Aim. To study the functional state of the segmental apparatus of lumbar and sacral parts of spinal cord of athletes engaged in biathlon and diving, and to reveal its potential functional and structural impairments by means of electroneuromyography.

Methods. Determination of nerve conduction velocity along motor fibers of the major ankle nerves of the lower extremities (n.tibialis) as well as the method of H-reflexometry («Nicolet Viking Select», USA-Germany).

Results. In the first group electromyographic parameters were normal. The athletes in the second group had deviations in the EMG parameters from the established standard. The abnormalities were characterized by increase of thresholds of $\mathrm{H}$-and $\mathrm{M}$-responses, decrease in the amplitude of the $\mathrm{H}$ response and amplitude ratios of $\mathrm{H}$-and $\mathrm{M}$-responses. However, parameters of $\mathrm{M}$-responses as well as indices of nerve conduction velocity along n.tibialis showed no significant differences in both groups. It was suggested that these changes of ENMG-parameters were caused by compression, ischemia and hypoxia of spinal nerves that could accompany muscle blockade syndrome of intervertebral discs $\mathrm{L}_{4}-\mathrm{S}_{3}$. Probably, pathological changes affected mostly the structure of the afferent part of the monosynaptic reflex arc, which is more sensitive to compression than the efferent one. Syndrome of muscle blockade of intercostal discs could be caused by inadequate loading of lumbar and sacral spine. Conclusion. It was found that 17-28 \% of tested athletes, performing in biathlon and diving, have deviations in the electromyographic parameters from the established standard that could serve as diagnostic sign of muscle blockade syndrome of intervertebral discs $L_{4}-S_{3}$, caused by inadequate exercise stress of the lumbar spine. Our data confirm the high information content and accuracy of the stimulation electromyography method.

Key words: stimulation electromyography, neuromuscular system, H-reflex, athletes, muscle blockade syndrome of intervertebral discs. 
Постановка проблемы. Анализ последних исследований и публикаций. Высокий уровень физической работоспособности спортсмена, соответствующий требованиям современного спорта, обусловлен функциональными свойствами и состоянием всех систем организма, в том числе нервно-мышечной системы, которая является очень чувствительной к различным фризиологическим и патологическим процессам, происходящих в нем. Данные многих исследователей в области спорта высших достижений свидетельствуют о важности проведения контроля над состоянием организма спортсменов для оценки их готовности к выполнению напряженных фризических нагрузок, эфффективности функционирования различных фризиологических систем, степени мобилизации и использования резервных возможностей организма, направленности и эфффективности тренировочного воздействия нагрузок $[8,12,14,16]$.

Общепринятой является практика регулярного обследования высококвалифицированных спортсменов для оценки изменения функционального состояний их организма и дальнейшей индивидуальной коррекции тренировочного процесса. При этом оценивается состояние сердечно-сосудистой и дыхательной систем в покое и при фризической нагрузке, определяются биохимические показатели крови, измеряется содержание кальция в костной ткани, спортсмены проходят психофизиологические тесты [15]. В то же время исследование нервно-мышечной системы, которая является действующей частью двигательных систем человека, может существенно дополнить комплексную характеристику организма спортсмена [3, 18, 19].

Перспективным методом количественной оценки фрункционального состояния нервно-мышечной системы у спортсменов может быть исследование с использованием стимуляционной электромиографии, распространенное в клинике, в ходе которого обычно определяются параметры таких электронейромиографических феноменов, как Н-ресрлекс, который представляет собой моносинаптический рефрлекторный ответ, отводимый от мышцы (в данном случае камбаловидной мышцы голени) в условиях электрической стимуляции низкопороговых афрферентов (чувствительных волокон), которые проходят в составе смешанного (состоящего из афрферентных (чувствительных) и эфрферентных (двигательных, моторных)) волокон большеберцового нерва [2, 7]. Этот нерв, являющийся наибольшей ветвью седалищного нерва, сорормирован спинномозговыми нервами, берущими начало в поясничных и крестцовых сегментах спинного мозга $\left(\mathrm{L}_{4}-\mathrm{S}_{3}\right)$. Именно этот отдел позвоночника спортсмена испытывает большие нагрузки во время тренировок и соревнований. Таким образом, с помощью электронейромиографического исследования камбаловидной мышцы можно оценить состояние сегментарного аппарата поясничного и крестцового отделов спинного мозга.

Для комплексной электромиографической оценки функционального состояния сегментарного аппарата поясничного отдела спинного мозга целесообразным представляется также использование методики определения скорости проведения импульса (СПИ) по моторным волокнам большеберцового нерва. По литературным данным, СПИ находится в зависимости от многих фракторов, в том числе от диаметра нервного волокна и степени его миелинизации, кислотно-щелочного равновесия и электролитного обмена в тканях, окружающих нерв, температуры в зоне нервного ствола, температуры конечности в целом, а также от состояния периферического кровообращения в конечности. Снижение этого показателя ниже нормы может наблюдаться при демиелинизирующих поражениях нервных волокон либо быть следствием истончения волокон нерва (уменьшения площади поперечного сечения). Наличие фрактора компрессии нервного корешка и возможной ишемии нерва также может сопровождаться частичной или полной блокадой проводимости по нервному стволу [10, 11$]$.

Представляет интерес и выяснение причин формирования болевого синдрома нижней части спины у спортсменов. По современным представлениям, мышечная блокада межпозвонкового диска является пусковым процессом и одновременно основной сущностью заболевания; патологический процесс первично возникает в глубоких мышцах спины, главным образом, в межпоперечных мышцах поясницы и межостистых мышцах и заключается в чрезмерном напряжении этих мышц, превышающем их рабочие напряжения, что приводит к длительному, рефрлекторно закрепляемому спазму этих мышц. Сократившиеся мышцы оказываются в режиме самоблокировки. Развивается мышечная блокада межпозвонкового диска, вовлекающая в патологический процесс спинномозговые нервы и сопровождающие их сосуды. Компрессия спинномозговых нервов приводит к потере чувствительности органов и тканей, компрессия сосудов приводит к отекам и болевому синдрому $[4,6]$. На практике спортсмен обращается за помощью к врачу на такой стадии заболевания, которая требует приложения больших усилий, чтобы вернуть здоровье в полном объеме.

Таким образом, существует необходимость ранней диагностики нарушений функционирования нервно-мышечной системы для проведения своевременного лечения и предупреждения нарушений в будущем, с целью сохранения здоровья спортсмена и предоставления ему возможности продолжать активную спортивную жизнь. 
Работа выполнена согласно Сводному плану НИР Министерства образования и науки Украины по теме 2.35 «Критерии оценки функционального потенциала спортсменов высокого класса» (номер госрегистрации 0114U001482).

Цель исследования - оценка воздействия профессиональной деятельности спортсменов, специализирующихся в прыжках в воду и биатлоне, на фрункциональное состояние их нервно-мышечного аппарата.

Для достижения поставленной цели необходимо было исследовать функциональное состояние сегментарного аппарата поясничного отдела спинного мозга спортсменов и выявить его возможные фрункциональные и структурные нарушения с помощью методов электронейромиографии (ЭНМГ), а также изучить динамику ЭНМГ-параметров с течением времени; на основе полученных результатов создать рекомендации для спортсменов по корректировке тренировочного процесса для компенсации возможных нарушений функционального состояния нервно-мышечной системы.

Методы и организация исследования. В исследованиях приняли участие 65 спортсменов высокой квалификации (мастеров спорта и мастеров спорта международного класса), специализирующиеся в прыжках в воду и биатлоне, обоего пола в возрасте от 18 до 30 лет без неврологических заболеваний в анамнезе и признаков неврологической патологии на момент обследования.

Электронейромиографическое исследование проводили на нейродиагностическом комплексе «Nicolet Viking Select» (США-Германия). Использовали методику определения скорости проведения нервного импульса по моторным (двигательным) волокнам большеберцовых нервов нижних конечностей (n.tibialis), а также методику H-рефрлексометрии [2, 7, 10, 11].

Тестируемый спортсмен находился в положении лежа на животе, стопы свободно свисали с кушетки. Н-рефрлекс камбаловидной мышцы (m.soleus) вызывали биполярной чрезкожной стимуляцией большеберцового нерва (n.tibialis) в подколенной ямке. Для определения скорости проведения нервного импульса по моторным волокнам большеберцовых нервов проводили стимуляцию большеберцового нерва (n.tibialis) в подколенной ямке и области кзади от медиального надмыщелка и записывали М-ответы от мышцы короткого сгибателя пальцев нижней конечности (m.flexor hallucis brevis). Для регистрации электромиографических сигналов использовали пару стандартных поверхностных электродов с межэлектродным расстоянием 20 мм.

Анализировались следующие ЭНМГ-параметры: $\Pi_{H}$ и $П_{\text {м }}$ (пороги возникновения Н-ответа и М-ответа,
$\Pi_{H} / \Pi_{\mathrm{M}}$ (соотношение порогов возникновения $\mathrm{H}-$ и М-ответов), $\mathrm{H}_{\text {макс }}$ и $\mathrm{M}_{\text {макс }}$ (амплитуды максимального $\mathrm{H}$-ответа и максимального М-ответа), $\mathrm{H}_{\text {макс }} / \mathrm{M}_{\text {макс }}$ (соотношение амплитуд максимальных Н- и М-ответов в \%). Были также получены значения скоростей проведения импульса (СПИ) по моторным волокнам большеберцовых нервов. Анализировали показатели для правой конечности (ПК) и левой конечности (ЛК).

У спортсменов-биатлонистов были проведены две серии исследований - в 2013 и 2015 гг.; у спортсменов, специализирующихся в прыжках в воду, - также две серии - в 2014 и 2015 гг. По результатам исследований в каждой из серий спортсмены были разделены на две группы. В группе 1 ЭНМГ-параметры находились в пределах нормы, в то время как в группе 2 наблюдались значительные отклонения показателей от нормальных значений.

Статистическая обработка экспериментального материала осуществлялась с помощью пакета стандартных компьютерных программ математической статистики «Microsoft Excel», «Statistica-6». При проведении комплексных биологических обследований с участием спортсменов придерживались разработанной в лаборатории теории и методики спортивной подготовки и резервных возможностей спортсменов НИИ НУФВСУ «Программы комплексного биологического исследования особенностей функциональных возможностей спортсменов», а также законодательства Украины об охране здоровья и Хельсинской декларации 2000 г., директивы Европейского общества 86/609 относительно участия людей в медико-биологических исследованиях.

Результаты исследования и их обсуждение. Отклонения ЭНМГ-параметров были однонаправленными для групп спортсменов обоих видов спорта, исследуемых в первой и второй сериях тестов, и характеризовались тенденцией к увеличению соотношения порогов возникновения Н- и М-ответов, достоверным снижением амплитуд Н-ответов и соотношений амплитуд Н- и М-ответов (табл. 1, табл. 2). В то же время параметры М-ответов (порог, амплитуда) не имели достоверных отличий в двух группах. Это же касалось и скоростей проведения импульса по моторным волокнам n. tibialis. Необходимо отметить, что практически во всех случаях отклонения ЭНМГ-параметров от нормы сопровождались субъективными жалобами спортсмена на дискомфорт или боли в пояснично-крестцовой области, испытываемые им после повышенной нагрузки либо длительного нахождения в неудобной позе.

Известно, что увеличение значения соотношения порогов Н- и М-ответов (при выраженной патологии оно превышает единицу) отражает нарушение проведения возбуждения по чувствительным волокнам в 
ТАБЛИЦА 1 - Электронейромиографические показатели у спортсменов-биатлонистов в 2013 и 2015 гг.: сравнение групп нормы и нарушений (mean \pm se)

\begin{tabular}{|c|c|c|c|c|c|c|}
\hline \multirow{2}{*}{ ЭНМГ-параметр } & \multirow{2}{*}{ Норма } & \multirow{2}{*}{$\begin{array}{c}\text { Сторона } \\
\text { тела }\end{array}$} & \multicolumn{2}{|c|}{ Группа 1 (норма) } & \multicolumn{2}{|c|}{ Группа 2 (нарушения) } \\
\hline & & & 2013 r. & 2015 r. & 2013 r. & 2015 r. \\
\hline \multirow[t]{2}{*}{$\Pi_{H}, M A$} & \multirow[t]{2}{*}{$3-12$} & ПК & $10,5 \pm 1,0$ & $8,8 \pm 1,3$ & $11,9 \pm 3,7$ & $10,7 \pm 0,9$ \\
\hline & & ЛК & $9,4 \pm 0,8$ & $8,4 \pm 1,0$ & $12,1 \pm 4,7$ & $7,0 \pm 0,8$ \\
\hline \multirow[t]{2}{*}{$\Pi_{M}, M A$} & \multirow[t]{2}{*}{$5-20$} & ПК & $15,6 \pm 1,5$ & $14,3 \pm 2,4$ & $15,5 \pm 4,2$ & $11,8 \pm 0,6$ \\
\hline & & ЛК & $14,5 \pm 1,7$ & $13,0 \pm 1,7$ & $13,9 \pm 4,5$ & $7,5 \pm 1,3$ \\
\hline \multirow[t]{2}{*}{$\Pi_{H} / \Pi_{м}$, ус. ед. } & \multirow[t]{2}{*}{$<1$} & ПК & $0,69 \pm 0,04$ & $0,67 \pm 0,05$ & $0,76 \pm 0,04$ & $0,89 \pm 0,03$ \\
\hline & & ЛК & $0,69 \pm 0,03$ & $0,67 \pm 0,03$ & $0,85 \pm 0,06$ & $0,94 \pm 0,05$ \\
\hline \multirow{2}{*}{$\mathrm{H}_{\text {макс }}, \mathrm{MB}$} & \multirow[t]{2}{*}{$3-12$} & ПК & $6,5 \pm 0,9$ & $5,8 \pm 0,6$ & $1,8 \pm 0,5^{*}$ & $1,8 \pm 0,1^{*}$ \\
\hline & & ЛК & $7,4 \pm 0,9$ & $6,1 \pm 2,4$ & $1,2 \pm 0,4^{*}$ & $2,2 \pm 0,5^{*}$ \\
\hline \multirow[t]{2}{*}{$M_{\text {макс }}, M B$} & \multirow[t]{2}{*}{$3-15$} & $\Pi$ ПК & $10,5 \pm 1,1$ & $10,6 \pm 1,1$ & $11,0 \pm 1,8$ & $11,0 \pm 1,1$ \\
\hline & & ЛК & $12,3 \pm 1,1$ & $10,4 \pm 1,4$ & $11,0 \pm 2,8$ & $13,0 \pm 2,2$ \\
\hline \multirow[t]{2}{*}{$\mathrm{H}_{\text {макс }} / \mathrm{M}_{\text {макс }}, \%$} & \multirow[t]{2}{*}{$40-100$} & ПК & $62,5 \pm 5,6$ & $51,3 \pm 4,3$ & $15,7 \pm 1,5^{*}$ & $16,8 \pm 1,9^{*}$ \\
\hline & & ЛК & $58,6 \pm 5,5$ & $55,2 \pm 5,3$ & $10,7 \pm 0,9^{*}$ & $17,6 \pm 6,4^{*}$ \\
\hline \multirow[t]{2}{*}{ СПИ n.tibialis } & \multirow[t]{2}{*}{$35-55$} & ПК & $40,7 \pm 1,2$ & $42,1 \pm 1,2$ & $41,2 \pm 4,2$ & $46,0 \pm 2,0$ \\
\hline & & ЛК & $42,0 \pm 1,1$ & $40,4 \pm 0,9$ & $40,5 \pm 3,0$ & $45,3 \pm 5,3$ \\
\hline
\end{tabular}

*Достоверность различий между группами 1 и $2-\mathrm{p}<0,05$.

результате процессов, которые нарушают миелиновую оболочку нервных волокон или разрушают некоторые из них. Уменьшение ниже нормы (3 мВ) значения максимальной амплитуды Н-ответа позволяет говорить о снижении уровня общей рефлекторной возбудимости мотонейронного пула, а снижение значения соотношения амплитуд $\mathrm{H}_{\text {макс }} / \mathrm{M}_{\text {макс }}$ камбаловидной мышцы ниже нормы (40-100 \%) позволяет сделать вывод об уменьшении доли рефлекторно возбужденных альфа-мотонейронов из общего их числа в данной мышце [1, 3, 7].

Можно предположить, что отклонения ЭНМГпараметров от нормы наблюдались вследствие воздействия на спинномозговые нервы крестцового сплетения (сегменты $\mathrm{L}_{4}-\mathrm{S}_{3}$ ) комплекса фракторов - компрессии, ишемии и гипоксии, имеющих место при синдроме мышечной блокады межпозвонковых дисков (МБМД). По литературным данным, сила рефрлекторного спазма одних и тех же глубоких мышц спины может быть разной в зависимости от степени напряжения этих мышц, чем и определяется степень тяжести заболевания [6]. Вероятно, у спортсменов из группы 2 происходят патологические изменения в структурах дуги моносинаптического рефлекса, затрагивающие в основном ее афрферентную часть, являющуюся более восприимчивой к компрессии, ишемии и гипоксии.
Первичный патологический процесс, являющийся причиной возникновения синдрома МБМД, запускается вследствие несоответствия нагрузки и нагрузочных возможностей (объема и тренированности) межпоперечных мышц поясницы, межостистых мышц, а также мышц-вращателей. Следовательно, главными повреждающими напряжениями являются напряжения при боковых наклонных и вращательных движениях туловища. Именно в таких движениях принимают участие указанные мышцы. Другие причины - местное переохлаждение, заболевания внутренних органов, мышц - также могут запускать относительно легко протекающее самостоятельное заболевание или являются содействующими развитию основного тяжелого процесса [6].

Полученные результаты согласуются с данными исследований, в которых определялись различия показателей функционального состояния нервномышечной системы в группе нормы и в группе пациентов с остеохондрозом позвоночника [1]. Значения ЭНМГ-параметров и общие характеристики Н- и М-ответов оказались аналогичными для первой и второй групп.

В целом по результатам наших исследований, нарушение фрункционирования нервно-мышечной системы наблюдается у 17-28 \% спортсменов, что согласуется с литературными данными, согласно
ТАБЛИЦА 2 - Электронейромиографические показатели у спортсменов-прыгунов в воду в 2014 и 2015 гг.: сравнение групп нормы и нарушений (mean \pm se)

\begin{tabular}{|c|c|c|c|c|c|c|}
\hline \multirow{2}{*}{ ЭНМГ-параметр } & \multirow{2}{*}{ Норма } & \multirow{2}{*}{$\begin{array}{c}\text { Сторона } \\
\text { тела }\end{array}$} & \multicolumn{2}{|c|}{ Группа 1 (норма) } & \multicolumn{2}{|c|}{ Группа 2 (нарушения) } \\
\hline & & & 2014 r. & 2015 r. & 2014 г. & 2015 r. \\
\hline \multirow[t]{2}{*}{$\Pi_{H}, \mathrm{MA}$} & \multirow[t]{2}{*}{$3-12$} & ПК & $10,1 \pm 0,8$ & $9,1 \pm 0,7$ & $7,6 \pm 2,6$ & $7,4 \pm 1,0$ \\
\hline & & ЛК & $9,8 \pm 0,7$ & $8,3 \pm 0,6$ & $5,8 \pm 1,0$ & $8,6 \pm 1,1$ \\
\hline \multirow[t]{2}{*}{$\Pi_{M}, M A$} & \multirow[t]{2}{*}{$5-20$} & ПК & $8,1 \pm 0,8$ & $13,9 \pm 1,0$ & $9,0 \pm 2,0$ & $10,4 \pm 1,4$ \\
\hline & & ЛК & $9,4 \pm 0,9$ & $12,3 \pm 1,2$ & $6,7 \pm 1,0$ & $10,1 \pm 1,5$ \\
\hline \multirow[t]{2}{*}{$\Pi_{H} / \Pi_{м}$, ус. ед. } & \multirow[t]{2}{*}{$<1$} & ПК & $0,75 \pm 0,04$ & $0,68 \pm 0,05$ & $0,82 \pm 0,11$ & $0,72 \pm 0,07$ \\
\hline & & ЛК & $0,69 \pm 0,04$ & $0,70 \pm 0,03$ & $0,86 \pm 0,07$ & $0,85 \pm 0,09$ \\
\hline \multirow[t]{2}{*}{$\mathrm{H}_{\text {макс }}, \mathrm{MB}$} & \multirow[t]{2}{*}{$3-12$} & ПК & $5,7 \pm 0,8$ & $5,1 \pm 0,4$ & $2,9 \pm 0,4^{*}$ & $2,5 \pm 0,2^{*}$ \\
\hline & & ЛК & $5,2 \pm 0,7$ & $5,1 \pm 0,4$ & $2,4 \pm 0,4^{*}$ & $1,7 \pm 0,4^{*}$ \\
\hline \multirow[t]{2}{*}{$M_{\text {макс }}, M B$} & \multirow[t]{2}{*}{$3-15$} & ПК & $8,1 \pm 0,8$ & $8,1 \pm 0,7$ & $9,7 \pm 0,7$ & $7,0 \pm 0,8$ \\
\hline & & ЛК & $9,4 \pm 0,9$ & $8,4 \pm 0,6$ & $8,7 \pm 1,2$ & $7,0 \pm 0,9$ \\
\hline \multirow[t]{2}{*}{$\mathrm{H}_{\text {макс }} / \mathrm{M}_{\text {макс }}, \%$} & \multirow[t]{2}{*}{$40-100$} & ПК & $65,0 \pm 4,6$ & $64,6 \pm 4,6$ & $30,6 \pm 3,8^{*}$ & $36,3 \pm 1,9^{*}$ \\
\hline & & ЛК & $56,1 \pm 3,9$ & $63,2 \pm 4,5$ & $28,0 \pm 1,8^{*}$ & $24,3 \pm 1,8^{*}$ \\
\hline \multirow[t]{2}{*}{ СПИ n.tibialis } & \multirow[t]{2}{*}{$35-55$} & ПК & $40,8 \pm 1,2$ & $42,2 \pm 1,5$ & $44,7 \pm 0,6$ & $42,8 \pm 2,8$ \\
\hline & & ЛК & $39,6 \pm 0,8$ & $40,1 \pm 1,2$ & $41,4 \pm 2,6$ & $44,8 \pm 2,7$ \\
\hline
\end{tabular}

*Достоверность различий между группами 1 и 2 - p $<0,05$. 
которым около трети спортсменов нуждаются в индивидуальной коррекции с использованием медикобиологических мероприятий и примерно 10-20\%в коррекции тренировочного процесса [9].

Необходимо отметить, что мышечная блокада дисков, кроме негативного воздействия на соматическую нервную систему, неизбежно оказывает патологическое влияние на работу определенных внутренних органов посредством компрессии волокон нервов вегетативной системы, идущих в составе передних корешков и спинномозговых нервов. Лечение МБМД должно в любом случае начинаться с устранения рефрлекторного спазма глубоких мышц и заканчиваться устранением последствий такого спазма (отечной компрессии нервов с болевыми ощущениями, ограничения подвижности, нарушения чувствительности) [6]. К настоящему времени накоплен большой опыт консервативного (не хирургического) лечения синдрома МБМД, разработаны действенные методики, включающие комплексы упражнений, мягкое механическое воздействие и иглотерапию [4-6, 13, 17]. Важной задачей для фризиологов и спортивных врачей в сотрудничестве с тренерами является создание системы диагностических и лечебно-профилактических мероприятий, направленной на раннее выявление неблагоприятных влияний фризических нагрузок на функционирование нервно-мышечной системы спортсменов (первый этап) и разработку индивидуальной лечебной программы для каждого спортсмена, нацеленной на своевременное стимулирование восстановительных и компенсаторных возможностей организма спортсмена и возвращение его к полноценной тренировочной деятельности (второй этап).

\section{Литература}

1. АндрияноВа E. Ю. Электронейромиографические показатели и механизмы развития пояснично-крестцового остеохондроза / Е. Ю. Андриянова, Р. М. Городничев. Великие Луки, 2006. - 119 с.

2. Бадалян Л. О. Клиническая электромиография / Л. О. Бадалян, И. А. Скворцов. - М.: Медицина, 1986. 368 c.

3. Гехт Б. М. Электромиография в диагностике нервно-мышечных болезней / Б. М. Гехт, Л. Ф. Касаткина, М. И. Самойлов, А. Г. Санидзе. - Таганрог, 1997. - 370 с.

4. ДолженкоВ А. В. Остеохондроз / А. В. Долженков. - М.: АСТ, 2008. - 240 с.

5. Гончарук $К$. Механизм действия акупунктуры на примере лечения грыж межпозвонковых дисков / К. Гончарук. - М.: Сотис-Мед, 2009. - 215 с.

6. Жолондз М. Я. Новый взгляд на остеохондроз: причины и лечение / М. Я. Жолондз. - СПб.: Питер, 2010. - 157 с.

7. Зенков Л. Р. Функциональная диагностика нервных болезней: Руководство для врачей / Л. Р. Зенков. - М.: МЕДпресс-информ, 2004. - 488 с.
Таким образом, полученные нами данные подтверждают высокую информативность и достоверность ЭНМГ-метода исследования. С его помощью можно установить вид и степень нарушений функционального состояния нервно-мышечного аппарата, а также предоставить спортсмену конкретные рекомендации по профрилактике дальнейших патологических изменений или лечению.

\section{Выводы:}

1. Установлено, что у достаточно большой части исследуемых спортсменов, специализирующихся в биатлоне $(26-28 \%)$ и в прыжках в воду (17$22 \%$ ), наблюдаются отклонения ЭНМГ-параметров от нормы, что может служить диагностическим признаком синдрома мышечной блокады межпозвонковых дисков (одного или более) на уровне сегментов $\mathrm{L}_{4}-\mathrm{S}_{3}$ спинного мозга, вызванного воздействием неадекватной нагрузки на поясничный отдел позвоночника.

2. Близкие значения доли отклонений от нормы в разных группах исследуемых свидетельствуют о высокой повторяемости результатов в однородной группе спортсменов исследуемого вида спорта, а также подтверждают высокую информативность и достоверность ЭНМГ-метода исследования.

Перспективы дальнейших исследований. Предполагается проведение исследования по определению большего спектра электронейромиографрических показателей спортсменов, специализирующихся в разных видах спорта, выявление гендерных и возрастных особенностей для определения функционального состояния нервно-мышечной системы и разработки индивидуальных рекомендаций по коррекции тренировочного процесса и для повышения работоспособности спортсменов.

\section{References}

1. Andriyanova E. Y. Electroneuromyographic indices and mechanisms of osteochondrosis development / E. Y. Andriyanova, R. M. Gorodnichev. - Velikiye Luki, 2006. - 119 p.

2. Badalyan L. O. Clinical electromyography / L. O. Badalyan, I. A. Skvortsov. - Moscow: Meditsina, 1986. $368 \mathrm{p.}$

3. Gekht B. M. Electromyography in diagnostics of neuromuscular diseases / B. M. Gekht, L. F. Kasatkina, M. I. Samoylov, A. G. Sanidze. - Taganrog, 1997. - 370 p.

4. Dolzhenkov A. V. Osteochondrosis / A. V. Dolzhenkov. - Moscow: ACT, 2008. - 240 p.

5. Goncharuk K. Mechanisms of acupuncture action as exemplified by treatment of intervertebral discs / K. Goncharuk. - Moscow: Sotis-Med, 2009. - 215 p.

6. Zholondz M. Y. New outlook at osteoporosis: causes and treatment / M. Y. Zholondz. - Saint Petersburg: Piter, 2010. - $157 \mathrm{p}$.

7. Zenkov L. R. Functional diagnostics of nerve diseases: Manual for physicians / L. R. Zenkov. - Moscow: MEDpressinform, 2004. - $488 \mathrm{p}$. 
8. Иорданская Ф. А. Оценка специальной работоспособности спортсменов разных видов спорта: диагностика, механизмы адаптации, средства коррекции / Ф. А. Иорданская. - М.: Спорт, 1993. - 293 с.

9. КапилеВич Л. В. Физиологические методы контроля в спорте / Л. В. Капилевич, К. В. Давлетьярова, Е. В. Кошельская и др. - Томск: Изд-во Том. политех. ун-та, 2009. 172 с.

10. КоманцеВ В. Н. Методические основы клинической электронейромиографии: рук. для врачей / В. Н. Команцев. - СПб., 2006. - 349 с.

11. Николаев С. Г. Практикум по клинической электромиографии / С. Г. Николаев. - Иваново: ПресСто, 2013. - 394 c.

12. ПлатоноВ В. Н. Периодизация спортивной тренировки. Общая теория и ее практическое применение / В. Н. Платонов. - К.: Олимп. лит., 2013. - 624 с.

13. Ситель $A$. Соло для позвоночника / А. Ситель. М.: АCT, 2011. -250 с.

14. Короткий курс лекцій зі спортивної медицини / за ред. А. В. Смоленського. - М.: Фізична культура, 2005. 192 с.

15. Шинкарук О. А. Медико-біологічне забезпечення підготовки спортсменів збірних команд України з олімпійських видів спорту / О. А. Шинкарук, О. М. Лисенко, Л. М. Гуніна та ін. - К.: Олімп. л-ра, 2009. - 144 с.

16. Уилмор Д. Х. Физиология спорта / Д. Х. Уилмор, Д. Л. Костилл. - К.: Олимп. лит., 2001. - 503 с.

17. Хогсхед Н. Как победить астму / Н. Хогсхед, Дж. С. Казенс. - М.: ФАИР, 1998. - 304 с.

18. Clarys J. P. Electromyography in sports and occupational settings: an update of its limits and possibilities / J. P. Clarys // Ergonomics. - 2000. - Vol. 43. - P. 1750-1762.

19. Massó N. Surface electromyography applications in the sport / N. Massy, F. Reó, D. Romero et al. / / Apunts Med. Esport. - 2010. - Vol. 45, N 165. - P. 121-130.

markizalus14@gmail.com

olena_kolos@ukr.net

takhalyavka@ukr.net
8. Iordanskaya F. A. Assessment of special work capacity of athletes of different sports events: diagnosis, adaptation mechanisms, correction means / F. A. lordanskaya. Moscow: Sport, 1993. - 293 p.

9. Kapilevich L. V. Physiological methods of control in sport / L. V. Kapilevich, K. V. Davletyarova, E. V. Koshelskaya, Y. P. Bredikhina, V. I. Andreyev. - Tomsk: Tomsk Polytechnical University Publishing House, 2009. - 172 p.

10. Komantsev V. N. Methodical bases of clinical electroneuromyography. Manual for physicians / V. N. Komantsev. Saint Petersburg, 2006. - 349 p.

11. Nikolayev S. G. Clinical electromyography / S. G. Nikolayev. - Ivanovo: PressSto, 2013. - 394 p.

12. Platonov V. N. Sports training periodization. General theory and its practical applications / V. N. Platonov. - Kiev: Olimpiyskaya literatura, 2013. - 624 p.

13. Site/ $A$. Solo for spine / A. Sitel. - Moscow: ACT, 2011. - 250 p.

14. Brief course of lectures in sports medicine / edited by A. V. Smolensky. - Moscow: Fizychna kultura, 2005. 192 p.

15. Shynkaruk O. A. Medico-biological provision of preparation of athletes of national teams of Ukraine in the Olympic events / O. A. Shynkaruk, O. M. Lysenko, L. M. Gunina et al. - Kiev: Olimpiyskaya literatura, 2009. - 144 p.

16. Wilmore J. H. Physiology of sport / J. H. Wilmore, D. L. Costill. - Kiev: Olimpiyskaya literatura, 2001. - 503 p.

17. Hogshead H. How to defeat asthma / H. Hogshead, J. C. Kasens. - Moscow: FAIR, 1998. - 304 p.

18. Clarys J. P. Electromyography in sports and occupational settings: an update of its limits and possibilities / J. P. Clarys / / Ergonomics. - 2000. - Vol. 43. - P. 17501762.

19. Massó N. Surface electromyography applications in the sport / N. Massó, F. Rey, D. Romero et al. // Apunts Med. Esport. - 2010. - Vol. 45, N 165. - P. 121-130.

Поступила 10.05.2015 